Research Article

\title{
Simulation of the Conductive Process of Nano ZnO Varistors Based on Animation Plane Form
}

\author{
Xin Liu $(\mathbb{D}$ \\ College of Art and Design, Lanzhou Jiaotong University, Lanzhou 730070, Gansu, China \\ Correspondence should be addressed to Xin Liu; yunbogao@mail.lzjtu.cn
}

Received 11 July 2020; Revised 21 August 2020; Accepted 15 September 2020; Published 30 September 2020

Academic Editor: Tifeng Jiao

Copyright (c) 2020 Xin Liu. This is an open access article distributed under the Creative Commons Attribution License, which permits unrestricted use, distribution, and reproduction in any medium, provided the original work is properly cited.

\begin{abstract}
Among many nano materials and chemical materials, zinc oxide nanomaterials have attracted researchers' interest because of their high efficiency, low cost, easy preparation, and variable morphology. The purpose of this study is to explore the fabrication and conductive process of nano $\mathrm{ZnO}$ varistors under the simulation of an animation plane form. In this study, the chemical vapor deposition method was used to prepare nano $\mathrm{ZnO}$. Then, $\mathrm{ZnO}$ nanomaterials were mixed with deionized water to form a suspension. Under the action of a micromechanical stirrer, impurities were removed by heat treatment, and then different amount of water was added to obtain a nano $\mathrm{ZnO}$ electrode. The conductive process and electrochemical properties of the nano $\mathrm{ZnO}$ electrode were investigated and analyzed. The results show that the pressure ratio of the varistor increases obviously after adding nano $\mathrm{ZnO}$. In the range of $0-30 \%$, the pressure ratio of the $\mathrm{ZnO}$ varistor increases with the increase in nano $\mathrm{ZnO}$ content. When $w$ (nano $\mathrm{ZnO}$ ) is $30 \%$, the voltage ratio reaches 1.149 and the oxidation peak current ratio of LD decreases by 6\%. Therefore, it is concluded that the electrode of nano $\mathrm{ZnO}$ varistor valve sheets maintains good stability for a $\mathrm{LD}$ conductivity detection process. It also plays an important role in electrochemical research.
\end{abstract}

\section{Introduction}

In the rapid development of chemical materials, pressuresensitive zinc oxide valves are important equipment of zinc oxide thermometers. The properties of nano $\mathrm{ZnO}$ varistors mainly depend on the microstructure, material composition, and the function of raw materials. It represents a semiconductor valve plate with nonlinear bolt current intensity and is sensitive to electromotive force change. If the voltage is lower than the specified threshold voltage, the resistance value will rise and the current will hardly flow. However, if this threshold voltage exceeds (rheostat voltage), the resistance will change strongly and the current will immediately increase. Therefore, it is necessary to study the effect of $\mathrm{ZnO}$ particle size on the electrical properties of pressure-sensing valve discs.

Nano ZnO has many unique properties of nano materials, such as electrical conductivity, piezoelectricity, gas sensitivity, antibacterial, UV absorption, and scattering. Due to the advantages of nano $\mathrm{ZnO}$, such as light, electricity, magnetism, and sensitivity, it is used in gas sensors, thrusters, semiconductor materials, piezoelectric materials, antibacterial materials, UV shielding materials, thrusters, efficient catalysts, magnetic materials, thin film materials, and conductive materials.

According to the previous solid-state reaction method, Yang prepared $\mathrm{ZnO}$-based varistor ceramics by immobilizing $\mathrm{La}_{2} \mathrm{O}_{3}$ and doping $\mathrm{Y}_{2} \mathrm{O}_{3}$ differently. $\mathrm{He}$ used X-ray diffraction (XRD), scanning electron microscopy (SEM), and direct current tests to study the phase composition, microstructure, and electrical properties of the materials. XRD and SEM analyses showed the $\mathrm{Y}_{2} \mathrm{O}_{3}$ phase, $y$ phase, and La phase distributed in the grain boundary of $\mathrm{ZnO}$ particles. He also calculated that the average particle size of the primary stage was between 3.80 and $4.17 \mu \mathrm{M}$. The ceramics doped with $0.1 \mathrm{~mol} \% \quad \mathrm{La}_{2} \mathrm{O}_{3}$ and $0.5 \mathrm{~mol} \% \quad \mathrm{Y}_{2} \mathrm{O}_{3}$ exhibited high comprehensive electrical properties and a destructive electric field strength of $1055 \mathrm{v} / \mathrm{mm}$, a nonlinear coefficient of 65.5 , and a leakage current of $0.6 \mu \mathrm{A}$ at $1100^{\circ} \mathrm{C}$ for 
2 hours. Doping $\mathrm{La}_{2} \mathrm{O}_{3}$ and $\mathrm{Y}_{2} \mathrm{O}_{3}$ together with nano $\mathrm{ZnO}$ powder is a promising method to prepare pressuresensitive ceramics with excellent electrical properties. His method is inflammable in the preparation process, the success rate is not high, and the operation is inconvenient [1]. Nano $\mathrm{ZnO}$ powder containing nano $\mathrm{KNO}_{3}$ eutectic was synthesized by Liu instead of organic additives. The samples were characterized by XRD, transmission electron microscopy, inductively coupled plasma atomic emission spectrometry, X-ray fluorescence, electron differential system, and scanning electron microscopy. In the presence of $\mathrm{NaNO}_{3}-\mathrm{KNO}_{3}$ eutectic, spherical doped nano $\mathrm{ZnO}$ powder with a particle size of $20-37 \mathrm{~nm}$ can be obtained simply. His solvent mediated $\mathrm{NaNO}_{3}-\mathrm{KNO}_{3}$ eutectic contributed to the formation of uniformly dispersed doped $\mathrm{ZnO}$ nanocrystals. At $1100^{\circ} \mathrm{C}$ for 2 hours, the density of the $\mathrm{ZnO}$ varistor sintered in air is $5.43 \mathrm{~g} /$ $\mathrm{cm}^{3}$, which is equivalent to $96.9 \%$ of the theoretical density. The insulation breakdown voltage is $5893 \mathrm{v} / \mathrm{cm}$, and the nonlinear coefficient is 26.6. The addition of molten salt can prevent the varistor from agglomerating and improve the electrical properties of varistors. The coffee maker made by his method is easy to be damaged and has low reliability [2]. Tsukamoto studied the transient electric field and current density distribution in and around the metal oxide varistor with a diameter of $42 \mathrm{~mm}$ and a thickness of $36 \mathrm{~mm}$ using the finite difference time domain (FDTD) method. The current injected into the varistor is $4 \mu$ s lightning pulse current with a peak value of $100 \mathrm{kA}$ and a rise time of $4 \mu$ s. The battery has nonlinear resistance electric field characteristics in $X$, $Y$, and $Z$ directions. This is based on the measured nonlinear voltage current characteristics. In his FDTD analysis, in the case of lightning current with a rise time of $4 \mu \mathrm{s}$, the skin effect of $42 \mathrm{~mm}$-diameter varistors is not obvious. When the nonlinear characteristics of $\mathrm{ZnO}$ elements and other elements do not change, the distribution of electric field and current density is greatly affected, which will lead to the deterioration and failure of varistors. His method is only suitable for research, but not for large-scale production, and has greater limitations [3].

In this study, the crystal structure and characteristics of $\mathrm{ZnO}$ are introduced firstly, and then the material, application, and mechanism of nano $\mathrm{ZnO}$ pressuresensing valve discs are explained. This study illustrates the symptoms of planar animation. The preparation methods of six kinds of nano $\mathrm{ZnO}$ were summarized in detail. In this study, the calculation of electrochemical performance of nano $\mathrm{ZnO}$ pressure-sensing valve discs includes a resistance equation and nonlinear coefficient $\alpha$. In this study, the construction of a $\mathrm{ZnO}$ nano/ITO electrode, the analysis of the reproducibility and stability of the electrode, the analysis of the influence on the holding time of the electrical performance of $\mathrm{ZnO}$ varistor valves, and the experiment on the flattening of nano $\mathrm{ZnO}$ valves were carried out. Finally, the conclusion of this study is obtained by analyzing the conductive process and the composition of nano $\mathrm{ZnO}$ conductive materials.

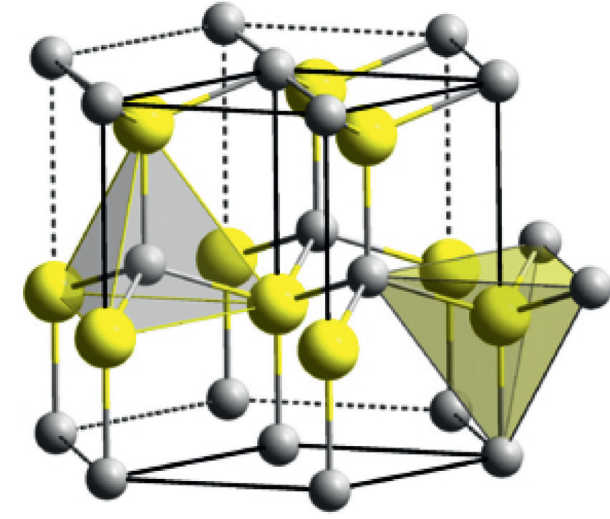

Figure 1: Atomic structure of nano $\mathrm{ZnO}$.

\section{Zinc Oxide Pressure-Sensitive Valve Piece and Animation Plane Form}

2.1. Crystal Structure and Properties of $\mathrm{ZnO}$. Electrical conductivity is one of the important properties of $\mathrm{ZnO}$. At room temperature, the resistivity of $\mathrm{ZnO}$ may reach below $0.068 \Omega \mathrm{cm}$. The conductivity of $\mathrm{ZnO}$ is closely related to its crystal structure [4]. The lattice structure of $\mathrm{ZnO}$ is representative of the wurtzite structure. The lattice constants are $a=0.3325 \mathrm{~nm}, c=0.521 \mathrm{~nm}$, and $c / a=1.6$. In the crystal structure, oxygen ions are arranged in hexagonal close packing, and similarly, zinc ions are also arranged in hexagonal close packing. Zinc ions form a Zn-04 coordination tetrahedron around the oxygen ion tetrahedron, and vice versa. In order to produce polar symmetry along the hexagonal axis, the zinc oxide of wurtzite is a polar structure. At the same time, this polarity brings some unique characteristics to $\mathrm{ZnO}$, such as high conductivity. Figure 1 shows the atomic structure of nano $\mathrm{ZnO}[5,6]$.

Nano $\mathrm{ZnO}$ is a white hexagonal crystal or powder, odorless, nontoxic, and delicate. A new type of high-performance micro inorganic material with a particle size of $1-100 \mathrm{~nm}$ was prepared. It is also known as zinc oxide. The relative density is $5.606 \mathrm{~g} / \mathrm{cm}^{3}$, the refractive index is $2.008 \sim 2.009$, and the melting point is $1975^{\circ} \mathrm{C}$. It is soluble in acid, sodium hydroxide, and ammonium chloride and insoluble in water, ethanol, and ammonia. It is an amphoteric oxide, which absorbs carbon dioxide and water from the air to form zinc carbonate. It turns yellow when heated and white after cooling. It does not allow ultraviolet light to penetrate and will not turn black when exposed to hydrogen sulfide $[7,8]$.

2.2. Application of Nano $\mathrm{ZnO}$ Varistors. It is used as a voltage regulator in TV receiver, CRT application equipment, lighting equipment, particle accelerator, and TV monitoring [9].

It is used as an overvoltage protection component in $\mathrm{CNC}$ lathe, automobile engine, loader, starter, copier, and telephone.

It is used as an overvoltage protection device in generator magnetization protection equipment and track system flash protection equipment [10]. 


\subsection{Mechanism of $\mathrm{ZnO}$ Varistors}

2.3.1. Conductive Mechanism. The band gap of $\mathrm{ZnO}$ is about $3.2 \mathrm{eV}$. At $27^{\circ} \mathrm{C}$, the composite stoichiometric nano $\mathrm{ZnO}$ valve plate must have insulation, but due to the existence of inherent defects, it becomes an extra energy space area where the cycle is disturbed. The existence of these extra energy spaces will lead to the formation of aggressive zinc atoms. The activation energy of the attacking zinc atoms is low, most of which are ionized at $27^{\circ} \mathrm{C}$. This is one of the reasons for the conductivity of $\mathrm{ZnO}$ conductive ceramics at room temperature. If there are no impurity ions, these conductive electrons mainly come from the ionization of interstitial zinc atoms, which presents the atomic electron conduction characteristics of nano $\mathrm{ZnO}$. When metal oxide impurities are introduced into zinc oxide, these metal ions act as donors or acceptors (which is different from the type of zinc oxide that forms solid solution and metal ions) and the conductivity of zinc oxide is greatly different $[11,12]$.

2.3.2. Aging Mechanism. The annual power change of varistor zinc oxide valve discs is mainly due to the increase of leakage, the decrease of no-load voltage, and the absolute condition of voltage current function after long DC voltage or large impulse current [13]. The main reason is the potential energy distortion caused by the falling of electrons, the change of dipole direction, oxygen dissociation, and ion diffusion. Among them, for example, the degradation caused by the first two conditions is the result of subsequent experiments. The degradation phenomenon and mechanism of $\mathrm{ZnO}$ pressure-sensitive valve discs are described negatively. The aging due to DC and AC is caused by the deformation of astigmatism-bound barriers. Other theories suggest that the aging due to DC and AC is caused by changes in Scottish barriers. According to their methodology, the important reasons for aging caused by DC and AC are ion transfer and diffusion, which may be related to oxygen and invasive zinc ions [14].

2.4. Forms of Planarization. "Plane" refers to surfing without ups and downs, where two connecting lines are on the same plane. In the field of art and design, "planarization" has two sides. On the other hand, "planarization" refers to the material plane of art and design works and the limitation of objective conditions. In other words, the material of the work is medium sized. Designers or artists use a variety of methods to create and express art in space $[15,16]$. On the other hand, "plane" refers to the plane visual effect that artists and designers make, not in the form of formal language but in combination with the configuration of image modeling elements. In order to convey the mood of the subjects, the flat performance was divided into the following three categories.

2.4.1. Imagery Expression. In order to obtain a pure planarization effect and abstract the abstract meaning of concrete and objective things, we refine and simplify the visual elements of traditional modeling, such as normal transformation, spatial distance method, and light and shadow change, to create creators in the art process. Because of the integration of aesthetic feelings and objective things, it will bring a peaceful impression to the audience's psychological level [17].

2.4.2. Abstract Expression. In the process of artistic creation, the creators give up the concept of traditional modeling, combine the basic elements such as pure point, line, surface, and color into unreasonable expression, and use bright morphological symbols to explain the spiritual connotation and realize the plane characteristics-very powerful visual effects.

2.4.3. Graphic Expression. In the process of artistic creation, the creator transforms various forms of expression space and three-dimensional space into plane graphics and color blocks for layout and combination, such as digital, traditional, and so on. The collage combination method can create simple, bright, and unique style of image effects [18].

\subsection{Preparation Method of Nano Zinc Oxide}

2.5.1. Chemical Vapor Deposition (CVD). Metal compound materials vaporize at a high temperature and then change the particles in the gas phase to obtain the required nano materials. The characteristics of this method are strong controllability and single product. The most important thing is that the quality of the extracted materials is very good, which can be used to observe and test the properties of materials [19].

2.5.2. Hydrothermal Method. In this method, the reagents are distributed into the solution according to a certain proportion at a high temperature and high pressure in a closed container and cooled at room temperature; the crystalline precipitate obtained from the reaction is cleaned and finally dried to obtain the required nano products. The hydrothermal process has the following advantages: simple equipment, simple operation, high uniformity, and high performance. The disadvantage is that the reaction time is long, the experimental process cannot be directly monitored, and the product cannot be controlled.

2.5.3. Carbothermal Reduction Reaction Deposition Method. In this way, the mixed material of $\mathrm{ZnO}$ and valve plate materials is heated in a special environment to cause a reduction reaction. The zinc vapor is used as a catalyst to oxidize it into liquid state and then oxidized to solid form to create a solid rosette. In addition, according to the pretreatment of the experimental substrate, $\mathrm{ZnO}$ nanomaterials can be prepared by this process without catalysts $[20,21]$.

2.5.4. Laser Pulse Deposition. The mechanism of this process is that under the laser irradiation, the target becomes water vapor. The steam is very hot and dense. In the case of 
transporting the gas, it condenses into nanostructures under the influence of liquid catalyst nanoparticles. Continuous growth in different environments and its growth diameter are limited by catalyst nanoclusters [22].

2.5.5. Sol-Gel Method and Microemulsion Method. These two processes are similar to the hydrothermal process, that is to say, transparent colloidal solution is formed after liquidphase reaction and nanoparticles are prepared by different treatment processes. Each of these two methods has its own advantages and disadvantages. The nanoparticles prepared by sol-gel method have high uniformity and high-purity particles, but they must undergo long time combustion and synthesis. The monodisperse interface of nanoparticles prepared by the microemulsion method is good [23].

2.5.6. Direct Precipitation Method. The principle of this method is to use soluble salt solution $\mathrm{NH}_{3}-\mathrm{H}_{2} \mathrm{O}$ and other substances under certain conditions. After a chemical reaction is formed and precipitated, the extra anions are washed away by precipitation, and finally, the precipitate is heated to obtain zinc oxide.

\subsection{Calculation of the Conductivity of Nano $\mathrm{ZnO}$ Varistors}

2.6.1. Resistance Equation. In the same measuring circuit, Scotty's contact voltage current ratio remains unchanged regardless of the length of $\mathrm{ZnO}$ nanoribbons associated with the circuit $[24,25]$. The total resistance of the circuit includes the contact resistance and the resistance of nano $\mathrm{ZnO}$ chemical bond, so the total energy is as follows:

$$
V=V_{\text {contact }}+V_{\text {belt }}=\left(R_{\text {contact }}+R_{\text {belt }}\right) I \text {. }
$$

$V$ represents the applied voltage, and $I$ is the corresponding current in the circuit. The electric density $J_{\mathrm{s}}$ for overcoming the barrier of hot electron emission is as follows:

$$
J_{\mathrm{s}}=-\frac{4 \pi q m^{*} k^{2} T^{2}}{h^{3}} \exp \left(-\frac{2 \varphi_{B}}{k T}\right) \exp \left(\left(\frac{q V}{k T}\right)-1\right) .
$$

The current equation of hot electron emission theory is as follows:

$$
\begin{aligned}
& J_{\mathrm{s}}=J_{0} \exp \left(\left(\frac{q V}{k T}\right)-1\right), \\
& J_{0}=A^{*} T^{2} \exp \left(-\frac{q \varphi_{B}}{k T}\right), \\
& A^{*}=-\frac{4 \pi q m^{*} k^{2}}{h^{3}},
\end{aligned}
$$

where $A^{*}$ is the Richardson constant, $\phi_{\mathrm{B}}$ is the Schottky barrier height, $h$ is the Planck constant, $T$ is the temperature, $K$ is the Boltzmann constant, $\mathrm{q}$ is the electron charge, and $V$ is the applied voltage. The Schottky contact voltage and resistance can be calculated by the following formula:

$$
\begin{aligned}
P_{\mathrm{C}} & =\lim _{V \longrightarrow 0}\left(\frac{\mathrm{d} V_{\text {contact }}}{\mathrm{d} J}\right)=\frac{K T}{q J_{\mathrm{s}}}, \\
R_{\text {contact }} & =\frac{P_{\mathrm{c}}}{A}=\lim _{V \longrightarrow 0} \frac{K T}{q J_{\mathrm{s}} A},
\end{aligned}
$$

where $J$ is the current density of the circuit, $A$ is the Scotty contact surface, and $V$ is the applied voltage.

Since the limit value of $P_{c}$ is used, the resistance value of Scotty contact resistance can be obtained. The resistance of nanoribbons connected to the circuit is obtained by subtracting a certain amount of random combined contact resistance from all resistors. The resistance is variable, and the magnitude of the change depends on the degree of oxidation in the zinc nanoribbon measurement circuit. The timing of the visit has changed. By adjusting the resistance point $\left(R_{\mathrm{b}}\right)$ and length $(d)$ of a single $\mathrm{ZnO}$ nanobelt, the curve of the index can be expressed by the formula of coefficient $\left(a_{1}=0568, a_{2}=03577\right)$ :

$$
R_{\mathrm{b}}=a_{1} \exp \left(a_{2} d\right) .
$$

The experimental formula is expanded, and the change of crystal resistance of nano $\mathrm{ZnO}$ materials is combined into a formula:

$$
R_{\mathrm{b}}=\frac{0.9625 d}{1-0.0565 d} .
$$

It can be seen from the formula that the resistance characteristics of nano $\mathrm{ZnO}$ do not conform to the classical Ohm's law. This shows that the resistance of the material varies linearly with the length.

2.6.2. Nonlinear Coefficient $\alpha . \alpha$ is an important parameter to explain the variable characteristics of nano $\mathrm{ZnO}$. Generally, the larger the $\alpha$ value is, the better the pressure sensitivity is. The formula is through a static resistance $R_{\mathrm{j}}$ to the dynamic resistance $R_{\mathrm{d}}$ :

$$
\begin{aligned}
\alpha & =\frac{R_{\mathrm{j}}}{R_{\mathrm{d}}}=\left(\frac{U / I}{\mathrm{~d} U / \mathrm{d} I}\right)=\frac{U}{I} \cdot \frac{\mathrm{d} I}{\mathrm{~d} U}, \\
\frac{\mathrm{d} I}{I} & =\alpha \frac{\mathrm{d} U}{U} .
\end{aligned}
$$

After integration, we can get

$$
\begin{aligned}
\ln I & =\alpha(\ln U-\ln K), \\
I & =\left(\frac{U}{R}\right)^{\alpha} .
\end{aligned}
$$

$U$ is the applied voltage, $I$ is the flow rate, and $K$ is the material coefficient. By measuring the voltage $U_{\mathrm{a}}$ and $U_{\mathrm{b}}$ and the corresponding $I_{\mathrm{a}}$ and $I_{\mathrm{b}}$ on the varistor, the nonlinear coefficient $\alpha$ can be obtained:

$$
\alpha=\frac{\lg I_{\mathrm{a}}-\lg I_{\mathrm{b}}}{\lg U_{\mathrm{a}}-\lg U_{\mathrm{b}}}=\lg \left(\frac{\left.I_{\mathrm{a}} / I_{\mathrm{b}}\right)}{\lg \left(U_{\mathrm{a}} / U_{\mathrm{b}}\right)}\right.
$$




\section{Conducting Process Experiment of Nano ZnO Valves in a Plane Form}

\subsection{Experimental Equipment}

(1) Measuring instruments: analytical balance and ordinary balance.

(2) Powder mixing unit: QM-ISP04 planetary drilling rig.

(3) Drying/heat treatment equipment: electric constant temperature drying oven and $\mathrm{KXX}-12-16 \mathrm{~A}$ resistance furnace.

(4) Test device: MY-3 KV propeller tester.

(5) Microstructure analysis device: JSM-59000LV scanning electron microscope, X-650 scanning electron microscope, X'pertPro X-ray diffractometer, and V4150 electron spectrometer.

\subsection{Chemical Composition Design of Experimental Materials}

3.2.1. Raw Materials of Zinc Oxide. This is the main raw material accounting for more than $90 \%$ of all raw materials. In addition to using high-purity raw materials as much as possible, the qualified standards for the composition, shape, particle size, processing temperature, and bulk density of zinc oxide raw materials must be formulated. Zinc oxide powder was purchased for this study.

3.2.2. Additives. There are many kinds of additives (5-8) and are of a small amount (less than $5 \mathrm{~mol}$ in total), which are the basis of excellent electrical performance of zinc oxide pressure-sensing valve discs.

3.2.3. Composition and Formula of Experimental Materials. Table 1 shows the composition and formula of experimental materials.

3.3. Test for Performance and Structure. The varistor voltage $U_{1 \mathrm{~mA}}$, voltage ratio $U_{1 \mathrm{~mA}} / U_{0.1 \mathrm{~mA}}$, and leakage current $I_{0}$ of each sample were measured using a MYZ-3 varistor automatic tester. The measured electrical performance parameters were compared and analyzed. A JEOL JSM-5900I scanning electron microscope was used to analyze the microstructure of the sample, analyze the microscopic image of the sample, and calculate the particle size distribution.

3.4. Construction of $\mathrm{ZnO}$ Nano/ITO Electrodes. The nano $\mathrm{ZnO}$ bubbles are fused with ionic water to form a mixture, which is stirred at a uniform speed under the function of the instrument to disperse the mixture evenly. Then zinc oxide was evenly distributed on the surface of ITO by spray equipment, and ITO was removed after cooling the heating plate.

The specific electrode design process is as follows:

(1) The suspension was obtained by placing a $0.02 \mathrm{~g} \mathrm{ZnO}$ nano electrode in $20 \mathrm{~mL}$ ionic water.
(2) Place six pieces of clean ITO on the heating plate under the spraying device and seal both sides of ITO glass with a transparent tape. The reason is that nano $\mathrm{ZnO}$ will not cover the whole ITO surface, and the content of nano $\mathrm{ZnO}$ will increase during the electrochemical test.

(3) After the heating plate is heated to $100^{\circ} \mathrm{C}$, the distance between the spray gun and the spray gun is connected to $15 \mathrm{~cm}$. Spray air provides spray power, inserts zinc oxide into the center of the container, and sprays the spray suspension in a mist form. After the ITO is cooled, heat treatment at $450^{\circ} \mathrm{C}$ for one hour to remove impurities, and drop solutions with different contents to obtain nano zinc oxide materials/ ITO electrode are performed.

\section{Analysis of the Conductive Process of Nano ZnO Valve Plates in the Planar Form}

4.1. Detection and Analysis of Electrode Repeatability and Stability. The repeatability of DPV was measured by using a $40 \mu \mathrm{M}$ LD on a graphene/ZnO nanoflower-modified electrode array. A total of 15 repeatability experiments were carried out with an interval of 10 minutes. The results show that the relative standard deviation (RSD) is $2.1 \%$. The repeatability and stability of graphene/ZnO nanomaterials/ ITO electrodes are shown in Figure 2.

From Figure 2, it can be concluded that graphene/ $\mathrm{ZnO}$ nanoflowers/ITO electrodes have good repeatability in the detection of LD. All electrochemical tests were performed in $0.01 \mathrm{M}$ PBS solution. In order to prove the stability of the graphene/ZnO nanoflower electrode, we placed the graphene/ZnO nanoflower-modified electrode for one week and then continued to test the DPV of $20 \mu$ MLD every two days for two weeks. The results showed that the oxidation peak current of LD decreased by $6 \%$ compared with the initial value, so the graphene/ZnO nanoflower-modified electrode had good stability for LD detection.

4.2. Effect of Holding Time on Electrical Properties of $\mathrm{ZnO}$ Varistors. The sintering temperature is 1150 . Table 2 shows the electrical properties of the samples with different holding time.

The sintering temperature is 1150 . The variation of the electrical properties of the $\mathrm{ZnO}$ varistor valve piece with $1 \mathrm{~mA}$ varistor potential gradient and pressure ratio $\left(\mathrm{U}_{1 \mathrm{~mA}} /\right.$ $\mathrm{U}_{0.1 \mathrm{~mA}}$ ) with insulation pairs is shown. Figure 3 shows the effect of holding time on the voltage gradient and voltage ratio of $\mathrm{ZnO}$ varistors.

It can be seen from Figure 3 that in the time range of $2-4$ hours, with the extension of holding time, the varistor potential gradient of the zinc oxide varistor valve plate decreases, and the pressure-sensitive potential gradient of the zinc oxide pressure-sensitive valve piece after holding for 4 hours is almost double that of holding for 2 hours. In the time range of 2-2.5 hours, the pressure ratio of the zinc oxide pressure-sensitive valve decreases with the extension of holding time. In the time range of $2.5-4$ hours, with the 
TABLE 1: Material composition.

\begin{tabular}{lccccccc}
\hline \multirow{2}{*}{ Number } & \multicolumn{7}{c}{ Component\% } \\
& $\mathrm{Bi}_{2} \mathrm{O}_{3}$ & $\mathrm{Sb}_{2} \mathrm{O}_{3}$ & $\mathrm{Cr}_{2} \mathrm{O}_{3}$ & $\mathrm{Co}_{2} \mathrm{O}_{3}$ & $\mathrm{MnO}_{2}$ & $\mathrm{ZnO}^{2}$ & $\mathrm{Nd}_{2} \mathrm{O}_{3} / \mathrm{CeO}_{2} / \mathrm{La}_{2} \mathrm{O}_{3}$ \\
\hline $1 \#$ & 0.7 & 1.0 & 0.5 & 0.8 & 0.5 & Allowance & 0 \\
$2 \#$ & 0.7 & 1.0 & 0.5 & 0.8 & 0.5 & Allowance & 0.02 \\
$3 \#$ & 0.7 & 1.0 & 0.5 & 0.8 & 0.5 & Allowance & 0.04 \\
$4 \#$ & 0.7 & 1.0 & 0.5 & 0.8 & 0.5 & Allowance & 0.06 \\
$5 \#$ & 0.7 & 1.0 & 0.5 & 0.8 & 0.5 & Allowance & 0.08 \\
$6 \#$ & 0.7 & 1.0 & 0.5 & 0.8 & 0.5 & Allowance & 0.1 \\
\hline
\end{tabular}

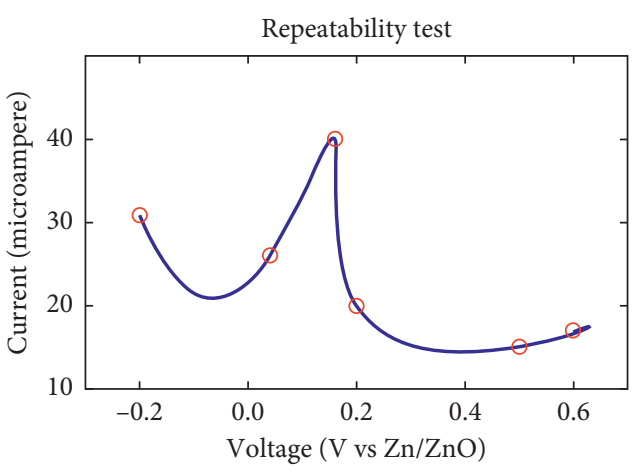

(a)

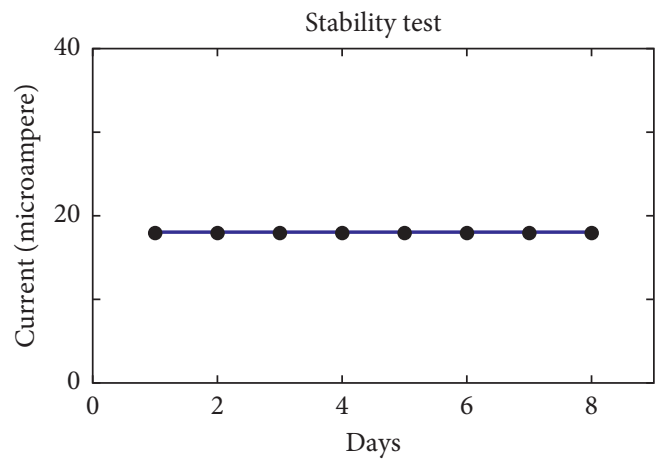

(b)

FIGURE 2: Repeatability and stability of graphene/ZnO nanomaterials/ITO electrodes.

TABLE 2: Conductivity of samples with different holding time.

\begin{tabular}{lcc}
\hline Holding time (hours) & $\begin{array}{c}1 \mathrm{~mA} \text { varistor gradient } \\
(\mathrm{V} / \mathrm{mm})\end{array}$ & $\mathrm{U}_{1 \mathrm{~mA}} / \mathrm{U}_{0.1 \mathrm{~mA}}$ \\
\hline 2 & 446.27 & 1.224 \\
2.5 & 375.96 & 1.089 \\
3 & 332.16 & 1.157 \\
3.5 & 309.45 & 1.201 \\
4 & 262.87 & 1.297 \\
\hline
\end{tabular}

further extension of holding time, the pressure ratio of the zinc oxide pressure-sensitive valve plate shows an increasing trend and the pressure ratio of 2.5 hours is the smallest. Considering the main electrical performance indexes of pressure-sensitive valves (high pressure-sensitive potential gradient and low pressure ratio), when the holding time is 2.5 hours, the voltage gradient is higher and the pressure ratio is minimum. Therefore, 2.5 hours is the best holding time.

In the process of preparation, temperature is the main stage. The components of this stage of material will undergo sufficient physical and chemical changes, so as to obtain compact sintered body without raw or over burning. Prolonged holding time can make the reaction between additives and between additives and zinc oxide complete, and the homogeneity of each phase is good, which is conducive to the recrystallization of the liquid phase and can promote the grain growth, so the varistor potential gradient decreases. In addition, with the increase in holding time, the grain distribution is more uniform and the ceramic structure is more compact, so the nonlinear coefficient increases and the pressure ratio decreases. However, if the holding time is too long, the volatilization of $\mathrm{Bi}_{2} \mathrm{O}_{3}$ in raw materials will be intensified, which will affect the quality of grain boundary layers. As a result, porosity increases, bulk density decreases, resistivity decreases, and nonlinear coefficient and other electrical properties deteriorate.

When nano $\mathrm{ZnO}$ is added into the varistor, the varistor voltage increases significantly. In the range of 0 to $30 \%$, with the increase of nano $\mathrm{ZnO}$, the influence voltage of pressuresensitive $\mathrm{ZnO}$ varistors increases. When $w$ (nano $\mathrm{ZnO}$ ) is $30 \%$, the varistor voltage is about $547.54 \mathrm{~V} / \mathrm{mm}$, which is about $54 \%$ higher than that of ordinary $\mathrm{ZnO}$ varistors without nano $\mathrm{ZnO}$ (about $354.42 \mathrm{~V} / \mathrm{mm}$ ). When nano $\mathrm{ZnO}$ is added into the varistor, the pressure ratio is increased significantly. In the range of $0-30 \%$, the pressure ratio of $\mathrm{ZnO}$ varistors increases with the increase of nano $\mathrm{ZnO}$ content. When $w$ is $30 \%$, the maximum pressure ratio is 1.149 . In the range of $0 \%$ to $10 \%$, the leakage current of $\mathrm{ZnO}$ varistors decreases with the increase of nano $\mathrm{ZnO}$ content and increases with the increase of nano $\mathrm{ZnO}$ content in the range of $10 \%-30 \%$. When $w$ (nano $\mathrm{ZnO}$ ) is $10 \%$, the minimum leakage current is $0.6 \mu \mathrm{A}$.

\subsection{Analysis of the Conducting Process of the Planarized Nano} $\mathrm{ZnO}$ Valve Piece. A 3D image of the $\mathrm{ZnO}$ nanobelt obtained through a scanning microscope shows that it is 30 microns wide and 1.5 microns thick and the surface of the sample is very smooth. The physical contact between the surface of $\mathrm{ZnO}$ nanoribbons and the platinum-plated conductive probe was established using atomic force microscope (AFM) contact mode. Thus, a closed circuit was formed to measure the current voltage curve. One of the 


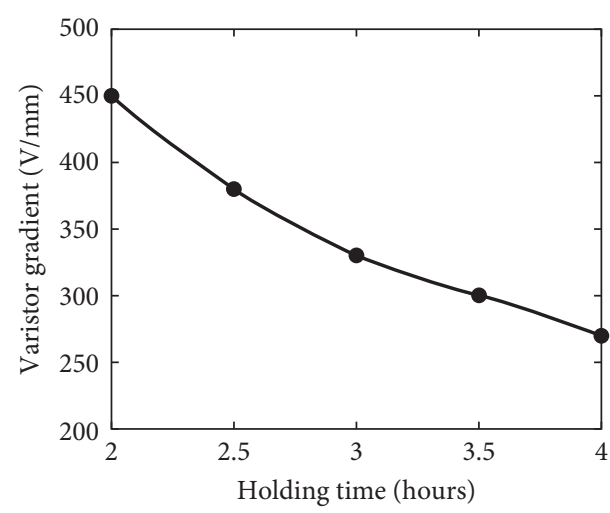

(a)

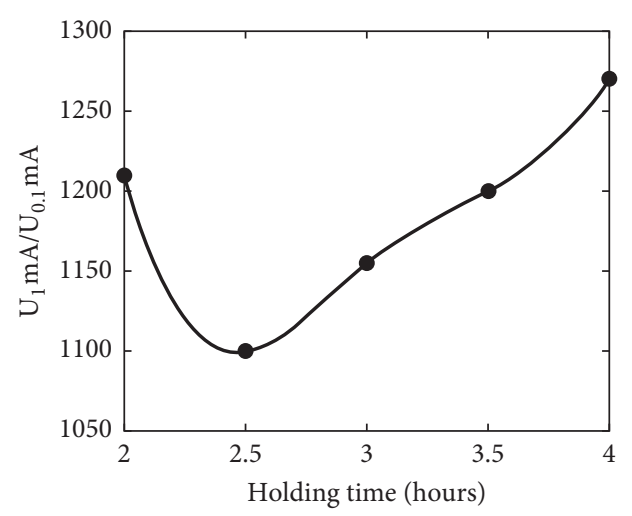

(b)

FIGURE 3: Effect of holding time on voltage gradient and voltage ratio of $\mathrm{ZnO}$ varistors.

characteristics of AFM is that it can select the contact position with $\mathrm{ZnO}$ nanobelts, so that a constant force can be maintained in the measurement to reduce the system error. When one end of the circuit is grounded, the voltage applied to the $\mathrm{ZnO}$ nanoribbon is negative. The type of thermoelectric elements is defined, the temperature is set at room temperature, and the isotropic and anisotropic characteristics of zinc oxide are simulated using software. Figure 4 shows the planar form of the conducting process of nano $\mathrm{ZnO}$ valve sheets.

It can be seen from Figure 4 that the surface atomic mobility of nano $\mathrm{ZnO}$ particles is high. In the sintering process, the nano $\mathrm{ZnO}$ particles wrapped on the micro $\mathrm{ZnO}$ particles first transfer the atoms to the vacancies on the surface lattice of the micron particles, which reduces the surface activity of the micro particles, weakens the vacancy diffusion and mass transfer between the micro $\mathrm{ZnO}$ particles, and hinders the grain boundary migration. The grain size decreases. On the one hand, the varistor voltage and other electrical properties of varistor valves are related to the number of grain boundaries between electrodes, and on the other hand, the number of some large grains in series. Therefore, the size and distribution of grains in varistor valve sheets are important grain microstructure parameters, which directly affect the electrical properties of varistor valves.

4.4. Composition Analysis of Nano $\mathrm{ZnO}$ Conductive Materials. TEM and XRD spectra of conductive $\mathrm{ZnO}$ powder heat treated at $500^{\circ} \mathrm{C}$ for $1.5 \mathrm{~h}$ in $\mathrm{H}_{2}$ atmosphere were studied. The distribution of $\mathrm{ZnO}$ particles is spherical, the particle size is relatively uniform, and the particle size is between $30 \mathrm{~nm}$ and $40 \mathrm{~nm}$. There is a certain degree of agglomeration between the particles, which is consistent with the SEM observation. It can be seen from the XRD spectra that the sample is a single hexagonal system. When the spectrum is locally enlarged, the diffraction peaks of doping $\mathrm{m}^{3+}$ can be found at the places of 2e 59.3470 and 65.2390 , but the intensity is very weak, which indicates that the dissolution amount of $\mathrm{ZnAl}_{2} \mathrm{O}_{4}$ is very small. The average particle size calculated from the half peak width of the formula is about

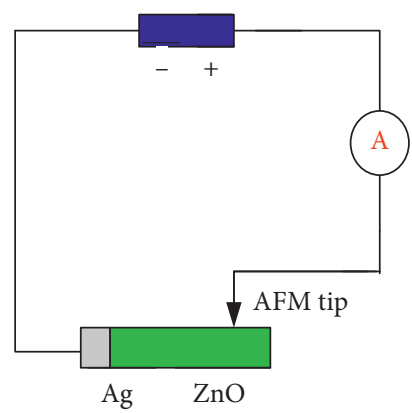

Figure 4: Planar form of conducting process of nano $\mathrm{ZnO}$ valve sheet.

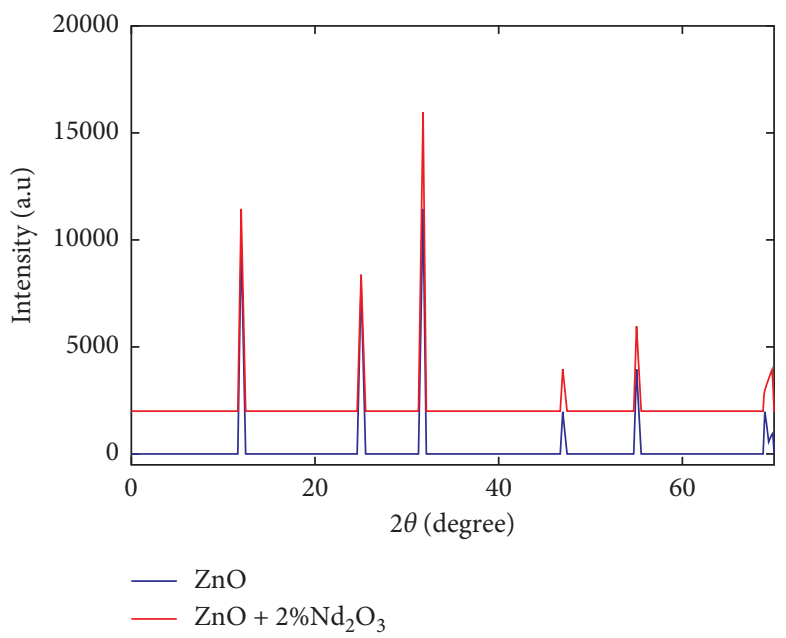

FIgURE 5: XRD spectrum of conductive $\mathrm{ZnO}$ powder.

$36 \mathrm{~nm}$, which is also roughly consistent with the observation of TEM photos, indicating that each particle is basically composed of single crystal. As shown in Figure 5 is the XRD spectrum of conductive zinc oxide powder.

It can be seen from Figure 5 that the peak value of $\mathrm{ZnO}$ reaches 1400 , and the peak value increases again to 1600 after adding $\mathrm{Nd}_{2} \mathrm{O}_{3}$. The bet value of conductive zinc oxide powder is 
$24.4 \mathrm{~m}^{2} / \mathrm{g}$, which is basically consistent with the results observed by TEM and calculated by half peak width of XRD. The results of XPS analysis showed that there was an obvious $\mathrm{Zn}_{2} \mathrm{p}$ peak at $1021.0 \mathrm{ev}$ and an obvious $\mathrm{Al}_{2} \mathrm{~S}$ peak at $118.6 \mathrm{ev}$, which indicated that the zinc oxide sample did contain AL. The results of XPS analysis showed that the $\mathrm{Zn}$ and can in the samples appeared in bivalent and trivalent forms respectively from the peak pattern of local amplification of XPS spectra, and there was no other valence state of these two elements.

\section{Conclusion}

When nano $\mathrm{ZnO}$ is added to the valve disc with high sensitivity, the voltage of the varistor will increase greatly. In the range of up to $30 \mathrm{wt} \%$, the varistor voltage of the $\mathrm{ZnO}$ pressure-sensitive valve disc increases greatly with the increase in nano $\mathrm{ZnO}$ content. When adding $0-30 \%$ nano $\mathrm{ZnO}$ into the induction valve, the pressure ratio increases with the increase in nano $\mathrm{ZnO}$ content; within $10 \%$, with the increase in nano $\mathrm{ZnO}$ dosage, the leakage current of the varistor zinc oxide valve plate decreases; in the range of $10 \%$ to $30 \%$, with the increase in nano $\mathrm{ZnO}$ content, the leakage current increases; because nano $\mathrm{ZnO}$ is added to the pressure valve plate, $\mathrm{ZnO}$ particle size is reduced.

When the sintering temperature is $1150^{\circ} \mathrm{C}$, the pressure gradient of the varistor $\mathrm{ZnO}$ valve disc is larger and the pressure ratio is the smallest. The best sintering temperature is $50^{\circ} \mathrm{C}$. When the constant temperature state is 2.5 hours, the induced voltage potential of the material is the highest and the voltage ratio is the smallest, so two 2.5 hours is the best constant temperature state. The potential radius of the varistor zinc oxide valve plate increases sharply and the leakage current decreases with the addition of diluted upper oxide $\mathrm{Nd}_{2} \mathrm{O}_{3} \mathrm{CeO}_{2} \mathrm{La}_{2} \mathrm{O}_{3}$. In principle, the pressure ratio does not change but slightly decreases.

In this study, an experimental device was installed to measure the voltammetric characteristics of $\mathrm{ZnO}$ nanobelts. The results show that there is a specific ratio between the resistance of the chemical bond and the material length and nonlinearity. The change in the conductivity of $\mathrm{ZnO}$ nanomaterials was analyzed by a finite element method. Under isotropic conditions, the current density distribution of nano $\mathrm{ZnO}$ varistors is very uniform. Under the anisotropic condition, the current density is mostly distributed on the surface of nano $\mathrm{ZnO}$ varistors. Nano zinc/ITO electrodes have good electrochemical performance. The sensitivity of the electrode to $\mathrm{LD}$ is $0.32 \mu \mathrm{A} / \mu \mathrm{m}$ in the range of $1 \sim 60 \mu \mathrm{M}$. At the same time, graphene/ZnO nanoflowers/ITO electrodes also have excellent selectivity, stability, and reproducibility for LD.

\section{Data Availability}

No data were used in the study.

\section{Conflicts of Interest}

The authors declare that they have no conflicts of interest.

\section{Acknowledgments}

This work was supported by the 2018 Gansu Provincial Science and Technology Plan Project "Research and Creation of Western Type Film and Television Brands in the Context of the Belt and Road Initiative," project number: 18CX1ZA011, and the 2017 Lanzhou Jiaotong University School-Level Youth Project "Building a Multi-Ethnic Dunhuang Silk Road under the Belt and Road" Strategy Featured Film and Television Brands, project number: 2017023.

\section{References}

[1] S. Yang and D. Zhu, "Effect of co-doping $\mathrm{Y}_{2} \mathrm{O}_{3}-\mathrm{La}_{2} \mathrm{O}_{3}$ on microstructure and electrical properties of $\mathrm{ZnO}$-based varistor ceramics prepared from nanosize $\mathrm{ZnO}$ powder," Journal of Materials Science: Materials in Electronics, vol. 29, no. 4, pp. 3104-3109, 2018.

[2] T.-T. Liu, M.-H. Wang, H.-P. Zhang, and Y.-Z. Zhao, "Molten salt synthesis of doped nanocrystalline $\mathrm{ZnO}$ powders and applications in varistor ceramics," Journal of Materials Science: Materials in Electronics, vol. 27, no. 4, pp. 3704-3709, 2016.

[3] N. Tsukamoto, Y. S. Imato, and M. Ishii, "FDTD analysis of lightning impulse current distribution inside of $\mathrm{ZnO}$ varistor element," IEEJ Transactions on Power and Energy, vol. 136, no. 11, pp. 839-845, 2016.

[4] S.-K. Choi, S.-M. Kang, J.-B. Lee et al., "Surge energy capability of $\mathrm{ZnO}$-based varistors according to the $\mathrm{Sb}_{2} \mathrm{O}_{3}$ and $\mathrm{Bi}_{2} \mathrm{O}_{3}$," Journal of Nanoscience and Nanotechnology, vol. 16, no. 12, pp. 12702-12707, 2016.

[5] N. Tsukamoto, T. Y. Tokita, and H. Okinaka, "Effects of aluminum doping on the electrical performance of $\mathrm{ZnO}$ varistor elements," Journal of the Japan Society of Powder and Powder Metallurgy, vol. 64, no. 4, pp. 139-144, 2017.

[6] Z.-Y. Zhao, M.-H. Wang, and H.-P. Zhang, "Microstructure and varistor properties of $\mathrm{V}$-doped $\mathrm{ZnO}$ nanoparticles prepared by co-precipitation method," Journal of Materials Science: Materials in Electronics, vol. 27, no. 2, pp. 1777-1782, 2016.

[7] J. Liu, X. M. Wang, and Y. Chen, "Dispersion of $\mathrm{ZnO}$ nanocrystals using ammonium polycarboxylate (AMP) for the fabrication of ZnO-based ceramics," Journal of Electronic Materials, vol. 49, no. 5, pp. 3216-3224, 2020.

[8] R. Yang, M.-H. X. Qu, and M. H. Wang, "Sol-gel synthesis of Ba-doped $\mathrm{ZnO}$ nanoparticles and its use in varistor ceramics," Micro \& Nano Letters, vol. 13, no. 10, pp. 1506-1509, 2018.

[9] F. Kharchouche and S. Belkhiat, "Effect of spark plasma sintering on microstructure and electrical properties of $\mathrm{ZnO}$ based varistors," Journal of Materials Science: Materials in Electronics, vol. 29, no. 19, pp. 16238-16247, 2018.

[10] W.-J. Sun, J.-R. Liu, D.-C. Yao, Y. Chen, and M.-H. Wang, "Synthesis of carbon-coated $\mathrm{ZnO}$ composite and varistor properties study," Journal of Electronic Materials, vol. 46, no. 3, pp. 1908-1913, 2017.

[11] M. A. Kurbanov, S. M. Ahadzade, I. S. Ramazanova, Z. A. Dadashov, and I. A. Faradzhzade, "Varistor effect in highly heterogeneous polymer-ZnO systems," Semiconductors, vol. 51, no. 7, pp. 953-958, 2017.

[12] Y.-H. Kim, "The effect of Sb2O3Additive on the electrical properties of $\mathrm{ZnO}$ varistor," The Transactions of The Korean 
Institute of Electrical Engineers, vol. 65, no. 10, pp. 1697-1701, 2016.

[13] S. H. Lee, C. K. Sohn, A. Djafar et al., "Ceramic Processing Research Electrical properties and microstructure of $\mathrm{ZnO}$ varistor with high surge protective characteristics," Journal of Ceramic Processing Research, vol. 20, no. 2, pp. 164-168, 2019.

[14] W.-J. Sun, R. Yang, M.-H Wang, and H.-P. Zhang, "Microstructure and varistor properties of $\mathrm{Pr}$-Co co-doped $\mathrm{ZnO}$ ceramics obtained by sol-gel method," Journal of Materials Science: Materials in Electronics, vol. 28, no. 14, pp. 1016610172, 2017.

[15] K. Zhang, E. S. Lee, I. M. Lee et al., "Photo-conductive detection of continuous $\mathrm{THz}$ waves via manipulated ultrafast process in nanostructures," Applied Physics Letters, vol. 112, no. 3, Article ID 031102, 2018.

[16] C. Wang, K. M. Zhang, H. X. WangGong, B. Guan, and Y. Zhang, "Intrinsically stretchable and conductive textile by a scalable process for elastic wearable electronics," ACS Applied Materials \& Interfaces, vol. 9, no. 15, pp. 13331-13338, 2017.

[17] N. Yin, P. K. Jain, P. Tandon et al., "Additive manufacturing of flexible electrically conductive polymer composites via CNCassisted fused layer modeling process," Journal of the Brazilian Society of Mechanical Ences \& Engineering, vol. 40, no. 4, p. 175, 2018.

[18] Y.-Y. Feng, S.-J. Chen, and Y.-L. Tu, "Development of a vibration-based electromagnetic energy harvester by a conductive direct-write process," Energies, vol. 10, no. 3, p. 337, 2017.

[19] K. He, C. P. Xie, B. Y. LiWang, M. Z. Rong, and M. Q. Zhang, "A facile and scalable process to synthesize flexible lithium ion conductive glass-ceramic fibers," RSC Advances, vol. 9, no. 8, pp. 4157-4161, 2019.

[20] F. Han, D. C. Venet, D. D. ChaussyCurtil, J. E. Broquin, and N. Reverdy-Bruas, "Fabrication of 3D conductive circuits: print quality evaluation of a direct ink writing process," $R S C$ Advances, vol. 8, no. 46, pp. 26036-26046, 2018.

[21] M. Vuong, D. Wu, Y. Liu et al., "Injection-compressioncompression process for preparation of high-performance conductive polymeric composites," Applied Composite Materials, vol. 26, no. 1, pp. 1-12, 2019.

[22] H. Dong, Y. X. Li, and L. S. ZhaoGuo, "A novel preparation method of electrically conductive adhesives by powder spraying process," Materials, vol. 12, no. 17, p. 2793, 2019.

[23] K. Khoshelham, "Closed-form solutions for estimating a rigid motion from plane correspondences extracted from point clouds," ISPRS Journal of Photogrammetry and Remote Sensing, vol. 114, pp. 78-91, 2016.

[24] H. Sofie, K. Bart, and P. Z. Revesz, "Affine-invariant triangulation of spatio-temporal data with an application to image retrieval," ISPRS International Journal of Geo-Information, vol. 6, no. 4, p. 100, 2017.

[25] A. C. Polycarpou and M. A. Christou, "Closed-form expressions for the on-Axis scattered fields by a subwavelength circular aperture in an infinite conducting plane," IEEE Transactions on Antennas and Propagation, vol. 65, no. 2, pp. 978-982, 2017. 